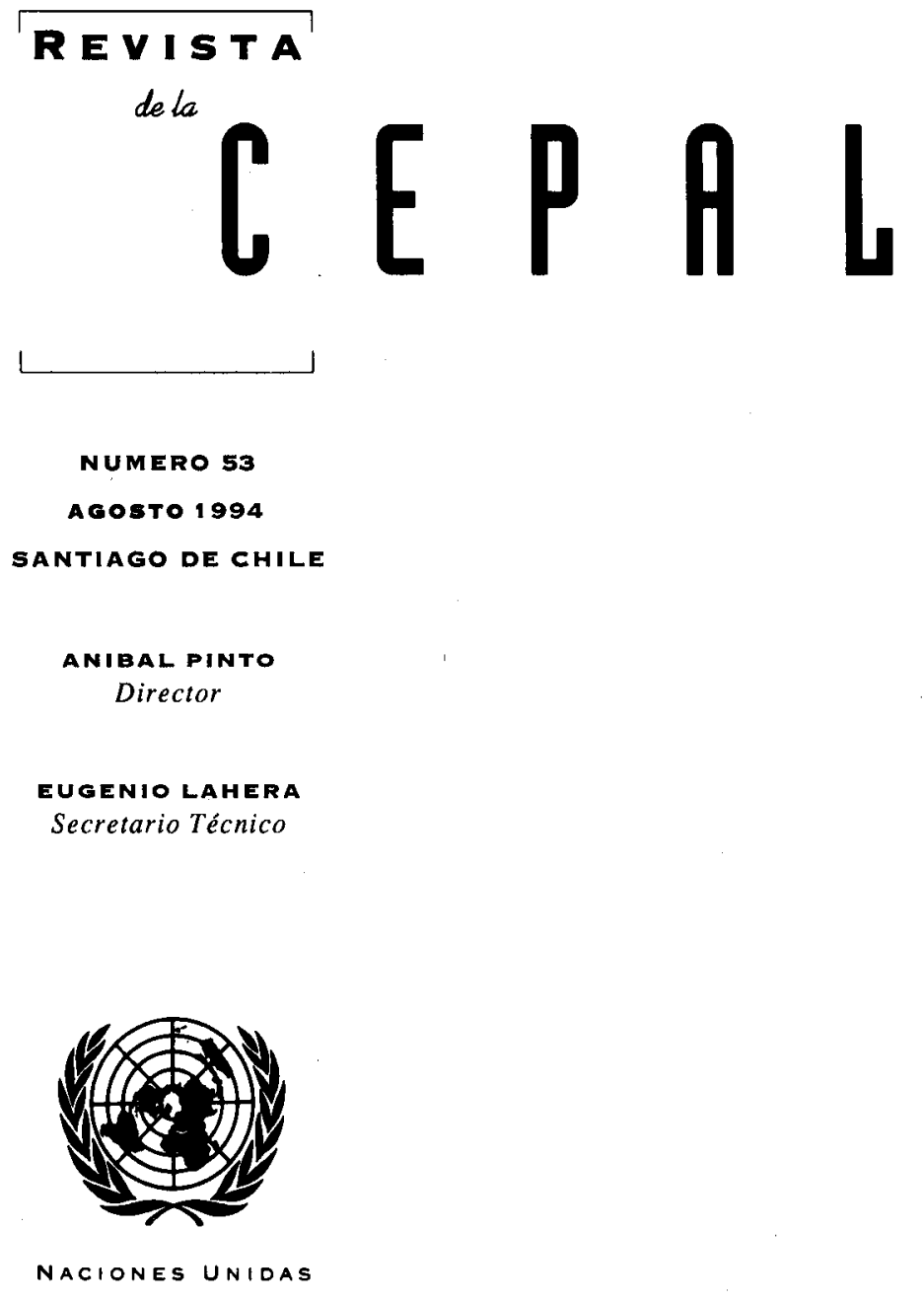


América Latina y el Caribe frente a la economía mundial

Gert Rosenthal

Afluencia de capitales externos y políticas macroeconómicas

Andras Uthoff y Daniel Titelman

Represión fínanciera y patrón de financiamlento latínoamericano

31

Marcos Antonio Macedo Cintra

Políticas de competitividad

49

Wilson Peres

Política industrial y fomento de la competitividad

Osvaldo Rosales

El regionalismo abierto y la integración económica

Juan A. Fuentes $K$.

Transformaciones del trabajo femenino urbano

91

Irma Arriagada

La gestión del agua y las cuencas en América Latina

Axel Dourojeanni

Políticas públicas y competitividad de las exportaciones

agrícolas

Milton von Hesse

Agroindustria y transformación productiva de la pequeña agricultura

Alejandro Schejtman

Grupos privados nacionales en México, 1988-1993

Celso Garrido

Evolución y perspectivas de la reforma y la apertura en China 


\section{Política industrial y fomento de la competitividad}

Osvaldo Rosales V.

Oficial de Asuntos

Económicos, CEPAL.
El debate regional sobre política industrial se centra hoy en las políticas de fomento de la competitividad en el contexto de economías abiertas. Privilegia el uso de políticas horizontales, se apoya en el mercado y es celoso en la vigilancia de los equilibrios macroeconómicos. Sin embargo, aún adolece de debilidades en el tratamiento de los temas sectoriales, sigue siendo renuente a asimilar las experiencias asiáticas de apoyo a pioneros, y de coordinación más estrecha entre el sector público y el privado, y aún no otorga suficiente importancia al fortalecimiento de la base tecnológica y de los recursos humanos. En este artículo se pasa revista a los acontecimientos internacionales que han modificado la noción de competitividad; se postula que la noción de políticas de fomento productivo es más pertinente que la de política industrial; se plantea que la transformación productiva en los años noventa está indisolublemente asociada a la internacionalización y a la profundización exportadora, y se examinan algunos instrumentos de política en los ámbitos del fomento a la exportación, la tecnología, la productividad y la capacitación. Se concluye con una reflexión sobre los requisitos de calidad en la gestión pública que surgen de este enfoque. 
I

\section{Introducción}

La política industrial ha estado asociada a la idea de intervención pública directa en la estructura productiva, de conformidad con determinadas visiones de futuro. En virtud de ella, se ha intentado identificar y promover sectores, y a veces empresas específicas, con mayor potencial de crecimiento. El enfoque tradicional hacía hincapié en las fallas del mercado para guiar el proceso de inversión, dada la presencia de externalidades y economías de escala. El accionar público, se suponía de manera implícita, podía lidiar eficazmente con tales imperfecciones. En la práctica, se subestimó la programación de las inversiones que realizan las empresas, y se sobrestimó la capacidad de gestión microeconómica de los gobiernos.

Las expresiones más radicales de política industrial han conducido a la práctica de escoger "ganadores", con resultados mixtos. En reacción, las posturas contrarias a cualquier modalidad de política industrial han visto en esa práctica un intento de anular el funcionamiento del mercado y de modelar políticamente la estructura económica (Lambsdorff, 1993).

Los enfoques más recientes, si bien ponen el acento en las imperfecciones del mercado (del capital, del trabajo y de los productos), no intentan reemplazar a éste en la asignación de los recursos de inversión. Buscan resolver directamente las fallas observadas, para así potenciar el papel asignador del mercado en las decisiones de producción. Además de las conocidas imperfecciones del mercado de capital (selección adversa, riesgo moral, segmentación), se observan fallas de coordinación, insuficiente provisión de bienes públicos como los de información, conocimiento, difusión tecnológica y capacitación, y debilidad de los procesos de aprendizaje a ellos asociados (Stiglitz, 1989).
En estrategias de economía abierta, la transformación productiva y el potencial de crecimiento están más asociados a las exportaciones, a un mayor énfasis en el desarrollo y la difusión tecnológicos como mecanismo para mejorar el posicionamiento de empresas nacionales en el mercado internacional. ${ }^{1}$

Por lo tanto, las políticas de desarrollo productivo apuntan actualmente:

i) al desarrollo de mercados hasta ahora incompletos - de tecnología, capital humano, capital de largo plazo, divisas--, superando la subinversión en exportación (nuevos productos, nuevos mercados) y el insuficiente apoyo a las empresas pioneras;

ii) al logro de rendimientos crecientes y complementariedades estratégicas que estimulen la competitividad sistémica;

iii) a la regulación de mercados de importancia crucial para la competitividad, como el sistema financiero, los servicios públicos de telecomunicaciones, la energía y otras áreas de la infraestructura (CEPAL, 1994a).

Con todo, el tema de las políticas de fomento productivo y tecnológico en economías abiertas es una asignatura pendiente en el debate regional: "En la actualidad, la actitud predominante es la de simplemente abandonar tales políticas en economías cerradas, sin que haya surgido un sustituto eficaz para fomentar la competitividad. Detrás del argumento en favor de políticas no discriminatorias, se puede gestar la creencia ingenua y sin fundamento empírico de que el mero funcionamiento de los mercados basta para encarar los temas de base en materia tecnológica, empresarial y de recursos humanos, de competitividad y de posicionamiento internacional" (CEPAL, 1994b).

\section{II}

\section{Cambios en la noción de competitividad}

\section{Globalización y cambio tecnológico}

La globalización y el cambio tecnológico están modelando actualmente el orden económico internacio- nal, a través de un marcado dinamismo de los merca-

\footnotetext{
1 Las nociones de eficiencia y posicionamiento en los mercados internacionales se examinan en CEPAL, 1992a, cap. V.
} 
dos financieros internacionales, de la inversión extranjera directa y de la exportación de servicios. Con ello, la dinámica económica ha pasado a ser predominantemente mundial y la distinción entre política económica interna y externa ha perdido parte de su sentido, pues los agentes económicos tienden a operar de modo de privilegiar el entorno internacional en sus decisiones. De allí que el principal criterio para calificar las políticas económicas sea hoy su aporte a la mejoría de la capacidad competitiva del país.

En un ambiente de acentuada globalización, el producto y el comercio mundiales crecen más lento que antaño, pero las aperturas comerciales y la paulatina reducción de barreras arancelarias al comercio aumentan la elasticidad-producto de las exportaciones mundiales. La inversión extranjera directa (IED), estrechamente asociada a las empresas transnacionales, aparece como uno de los factores más dinámicos en la promoción del crecimiento y la difusión tecnológica. En años recientes, los flujos mundiales de IED han triplicado el crecimiento del producto, en tanto que el crecimiento de las exportaciones ha duplicado el de la producción mundial (CET, 1991).

El poderío económico y comercial se mueve aceleradamente hacia el Pacífico. Se configura un nuevo mapa económico mundial de intercambios, con gestación deliberada de zonas comerciales, acuerdos de complementación productiva y tecnológica y procesos de convergencia de las políticas económicas (Rosales, 1993).

Tales tendencias a la regionalización del intercambio y a la construcción de grandes bloques comerciales estimulan los procesos de concentración de la IED en las principales economías, para minimizar los riesgos proteccionistas, para concentrar los recursos de investigación y desarrollo en las casas matrices de las empresas transnacionales y para reducir y compartir costos tecnológicos con socios e incluso con competidores a través de coinversiones y otras modalidades que acentúan la especialización y la adecuación flexible a la demanda.

El rápido incremento de los flujos de IED ha ido acompañado de un cambio en su composición sectorial, con una presencia cada vez mayor de los servicios. $^{2}$ En éstos, el componente tecnológico, de información y de conocimiento es cada vez más importante, de modo que los nuevos servicios constituyen un

2 Los servicios, que absorbían un cuarto de la IED mundial a comienzos de los años setenta, en la actualidad absorben la mitad de esa IED y entre 55 y $60 \%$ de los flujos anuales (CET, 1991). aspecto crucial de las estrategias de construcción de competitividad en la economía global. Tanto el rápido crecimiento del comercio en este rubro como la creciente orientación de la IED hacia él, son indicadores del grado de internacionalización de las economías (CET, 1991).

Los procesos de liberalización y desregulación financiera han acentuado la globalización de los mercados, imponiendo nuevas condiciones a la determinación de los tipos de cambio y tasas de interés. Los movimientos de capital desconectados del comercio exceden varias decenas de veces los del comercio y de la IED. Así, los movimientos de capital se han transformado en el principal factor de globalización y en fuerza conductora de la economía mundial (Drucker, 1993).

La transición tecnológica acrecienta la globalización de los mercados, la internacionalización de la producción y la competencia internacional. Factores decisivos en esta competencia son hoy la investigación científica y tecnológica ligada a la producción; la formación y actualización sistemática del recurso humano; las técnicas de gestión compatibles con la economía global, y las formas públicas y privadas de organización que estimulen la innovación, la flexibilidad y la creatividad.

Bajo tales procesos, lo que subyace como rasgo característico es que el conocimiento, expresado en educación, ciencia y tecnología, ha pasado a ser la clave del desarrollo económico y social y el principal código organizador de la sociedad de fines del siglo $\mathrm{XX}$. Lo que cuenta en la actual competencia entre naciones es la calidad de lo producido y la calidad de los recursos humanos involucrados en esa produccion.

$\mathrm{Al}$ crecer la importancia del conocimiento es natural que decline la ventaja competitiva vinculada a los recursos naturales, los salarios bajos o el empleo de baja calificación, y que se desplace hacia nuevas manufacturas y servicios en los que adquieren importancia la calidad, el diseño y la incorporación de tecnología (Lafay, 1989). Las ventajas competitivas que reclama el mercado mundial se basan en la inteligencia, el cambio técnico, la innovación y el valor agregado intelectual.

Con ello, las economías de productos primarios tienden a desconectarse de la nueva economía global. El cambio tecnológico ha estimulado el ahorro y la eficiencia en el uso de la energía y las materias primas, disminuyendo la elasticidad-ingreso de la demanda de productos primarios en la industria y los 
servicios, resintiéndose aquellas estrategias basadas en la explotación de recursos naturales. Como prueba de ello, el reciente ciclo expansivo en la economía mundial, el más largo de posguerra, coincidió con el nivel más bajo de los precios de los productos básicos (Drucker, 1993). El deterioro de tales precios no condujo a una recesión, como antaño. Las predicciones de escasez y elevados precios de las materias primas no sólo no se han concretado, sino que en el sector alimentario lo más probable es un exceso de oferta, dada la desaparición de grandes mercados importadores (China, India, la ex Unión Soviética) y su gradual transformación en exportadores de alimentos (CEPAL, 1992b).

\section{Competitividad-precio y competitividad es- tructural}

El enfoque tradicional asocia el fomento de la competitividad con la devaluación real y la disminución de los costos laborales unitarios, sea mediante incrementos de la productividad del trabajo o mediante reducciones del salario real (OCDE, 1992).

Un enfoque de este tipo puede poseer alto poder explicativo en presencia de mercados competitivos con alta elasticidad-precio en la demanda mundial de bienes transables, con productos homogéneos, y en los cuales los factores cualitativos que influyen en la capacidad comercial del país permanecen más bien constantes. Se reduce dicho poder explicativo si una fracción importante del comercio internacional responde a condiciones de competencia imperfecta ${ }^{3}$ y a una especialización intraindustrial, apoyada en la diferenciación de productos. En ese caso, las políticas de especialización productiva y de desarrollo tecnológico - y su impacto sobre la calidad y el diseño de los procesos y los productos- empiezan a influir de modo significativo en la captura de mercados, al tiempo que las consideraciones aisladas de precios relativos tienden a perder importancia para explicar la evolución de la competitividad.

En los productos estandarizados, la competencia opera por precios y disponibilidad. En los productos de especialización, lo más relevante son la calidad y el servicio; a continuación prima la entrega, y sólo a igualdad de estos factores entra a dirimir el precio.

3 En este sentido, los enfoques recientes de política comercial destacan la influencia de las economías de escala, las ventajas de la experiencia, la innovación y el aprendizaje tecnológico en los patrones de especialización (Krugman, 1991).
No se trata pues de que no interesen las consideraciones de precio y costo; pero en las nuevas condiciones de competitividad, la importancia relativa del precio es hoy menor (Pérez, 1988).

\section{Los elementos de la nueva competitividad}

En el mundo actual no compiten empresas sino sistemas. La empresa es el nudo crucial de la competitividad y la innovación, pero ella está integrada a una red de vinculaciones que incluye a sus proveedores de bienes y servicios, al sistema financiero, al sistema educacional, tecnológico, energético, de transportes, telecomunicaciones, entre otros, así como la infraestructura y la calidad del sector público y de las relaciones al interior de la propia empresa.

Los rezagos en estos ámbitos afectan la competitividad de la empresa. Construir sistemas de competitividad exige avances razonablemente simultáneos en la red de contactos que define a la empresa. Esto puede ser estimulado favoreciendo sistemáticamente la cooperación entre el sector público y el privado, y dentro del sector privado, así como la capacidad de establecer alianzas estratégicas de largo plazo, privilegiando en ellas el fomento de las exportaciones, la tecnología, la educación y la capacitación, con acuerdos flexibles de complementación y estrategias compartidas de internacionalización.

Este abordaje sistémico de la competitividad supera concepciones estrechas que limitan el examen de ella al tipo de cambio y a la balanza comercial. Como la "década perdida" lo mostró gráficamente, es posible conseguir significativos superávit comerciales con elevadas devaluaciones reales y su contraparte de compresión de las importaciones, reducciones en el salario real e incluso mermas en gasto social.

La verdadera prueba de la competitividad radica en medir la capacidad de las naciones para hacer frente a los desafíos de los mercados internacionales, y aumentar a la vez el bienestar de sus habitantes. La propuesta más elaborada al respecto sugiere considerar la evolución de cuatro indicadores: i) la productividad del trabajo; ii) el salario real; iii) la rentabilidad real del capital, y iv) la posición en el comercio internacional. ${ }^{4}$ Aun cuando en cada una de estas variables influye una diversidad de factores, su examen de conjunto ofrece un cuadro acertado de la evolución competitiva de los países.

\footnotetext{
4 Véase Report of the President's Commission on Industrial Competitiveness, Washington, D.C., 1985.
} 
La actual competitividad depende menos de ventajas salariales o de recursos naturales que de la calidad de los recursos humanos y de la capacidad de incorporación tecnológica. El fomento de la competitividad alude entonces a las políticas de formación de recursos humanos (educación, capacitación) y de fortalecimiento de la base tecnológica. Además, y como decisivas variables de entorno, la competitividad exige estabilidad macroeconómica y un funcionamiento fluido de los mercados.

La mantención de los equilibrios macroeconómicos -inflación baja y declinante, ahorro fiscal, fomento del ahorro e inversión, estímulo a la productividad y defensa del tipo de cambio real - constituye un requisito básico de la competitividad. La inestabilidad cambiaria, por ejemplo, aumenta los costos de transacción, acentúa la incertidumbre y puede frenar la inversión. Desde una perspectiva más amplia, es preciso profundizar la inserción internacional, perseverando en la estabilidad macroeconómica. Esto significa dar pasos adicionales en la diversificación comercial y en la apertura financiera, si bien con los necesarios resguardos de gradualismo, diversificación de cartera, cobertura de riesgo y fondos de estabilización, para reducir la transmisión de inestabilidades externas a la economía interna.

En otras palabras, es necesario acotar el ámbito de la competitividad al mejoramiento de la calidad de los factores productivos, subordinándola a la adecuada gestión macroeconómica y a la preeminencia de buenas políticas económicas. El fomento de la competitividad no es pues un sustituto de éstas, sino sólo un necesario complemento (Krugman), 1994).

La competitividad reclama también mercados competitivos, transparentes y de acceso fluido para los diversos agentes económicos. Mantener la estabilidad de los incentivos y reducir los costos de búsqueda, transacción e información, es otra forma de apoyar la competitividad.

Entonces, es sobre la base de preservar la estabilidad macroeconómica y de promover la competencia en los mercados que adquieren sentido las orientaciones en materia tecnológica, de capacitación, de infraestructura y de internacionalización productiva, que más adelante se detallan.

\section{Etapas de la competitividad}

No hay sugerencias de validez general en materia de políticas de competitividad y fomento productivo. Estas serán más o menos pertinentes según las especificidades nacionales que las condicionan de un modo crítico. En particular, influyen aquí el nivel y densidad de la base industrial y tecnológica, la especificidad de la inserción internacional, el peso relativo del comercio exterior sobre el producto, el grado de diversificación exportadora, la base empresarial y de recursos humanos, la calidad de la gestión pública y el grado de avance en las reformas económicas. El espectro de posibilidades que emana de la combinación de tales variables es una muestra también de las diversas posibilidades que surgen para abordar las distintas etapas de la competitividad.

Las reformas macroeconómicas - la estabilidad de precios, la disciplina fiscal, la reforma comercial, la consistencia de ella con la política macroeconómica y la credibilidad de las reformas mismas - constituyen el piso mínimo sobre el cual es posible ir construyendo la competitividad nacional. Tras tales reformas, la experiencia muestra la significativa contribución que hacen a la competitividad las reformas institucionales en materia de puertos (CEPAL, 1991), legislación laboral, modernización de aduanas e impuestos internos, entre otras.

En las economías que han avanzado más en las reformas macroeconómicas y en estas reformas institucionales, se plantea la necesidad de efectuar también reformas a nivel microeconómico y mesoeconómico, que aborden embotellamientos en materia de capacitación, productividad e infraestructura, ${ }^{5}$ así como los desafíos tecnológicos y de internacionalización productiva (en particular la inversión productiva en el exterior).

\section{III}

\section{¿Política industrial o política de desarrollo productivo?}

El actual debate sobre política industrial se centra en el fomento de la competitividad, por la vía de aumen-

\footnotetext{
${ }^{5}$ En lo referente a sugerencias de política para abordar la infraes-
}

tar la productividad total de los factores, mejorar la

tructura vial véase Schliessler y Bull (1992), y en materia de puertos, CEPAL (1991). 
calidad de los bienes y servicios y promover la generación y difusión tecnológicas.

La reflexión primera al respecto es que, en verdad, se trata de políticas de fomento productivo y tecnológico antes que de políticas industriales. Atrás han ido quedando los enfoques sectorialistas estrechos. El desafío actual es fortalecer la inserción internacional, orientando la estructura productiva en la dirección de las tendencias dinámicas del comercio mundial. Esto pasa por acrecentar el contenido de conocimientos y de valor tecnológico en cada producto, privilegiando la promoción de eslabonamientos productivos y de servicios en torno a las exportaciones, y estimulando los servicios a la producción, el desarrollo de proveedores y la producción de insumos intermedios y de bienes de capital asociados.

El desarrollo industrial moderno, articulado en torno a cadenas productivas, exige atender no sólo a la producción de bienes materiales sino a toda la gama de servicios vinculados a la producción, como mantenimiento, reparación, servicios de consultoría industrial, tecnológica, administrativa y financiera, programas computacionales, ingeniería de diseño y de proceso, y otros. La política industrial y de servicios modernos no puede desvincularse de las demás políticas sectoriales ni puede recluirse en enfoques sectorialistas.

Al reorientarse las estrategias de desarrollo en la región, el fomento productivo privilegia el apoyo a las nuevas industrias nacientes, esto es, a las exportaciones no tradicionales. Las empresas capaces de identificar un rubro de exportación y de colocarlo en mercados internacionales dinámicos en condiciones competitivas incurren en altos costos iniciales, propios de la penetración de mercados difíciles. Con su acción generan externalidades positivas - de información, prestigio, redes comerciales y otras- que favorecen a nuevos exportadores. De allí la importancia de compensar a las empresas innovadoras que incurren en los costos y riesgos de conquistar nuevos mercados (CEPAL, 1994a).

En aquellos casos exitosos de exportaciones basadas principalmente en los recursos naturales, corresponde consolidar las ventajas logradas, avanzando hacia las áreas de insumos, bienes de capital, tecnología y servicios asociados. De este modo se reorienta gradualmente el perfil exportador hacia productos de mayor valor agregado y contenido tecnológico, con mercados más dinámicos y precios más estables, y con menor riesgo de proteccionismo, reduciendo así la vulnerabilidad de la canasta de exportaciones.
Esto no significa polarizar una pugna entre productos primarios e industriales, pues lo relevante es el grado de conocimiento y tecnología que se incorpora en cada producto a la par con la promoción de cadenas productivas y de servicios en torno a las exportaciones. ${ }^{6}$

En la agricultura, por ejemplo, la distinción convencional entre cultivos en estado fresco (o no elaborado) y elaborado no representa necesariamente menor o mayor incorporación de valor agregado. En muchas ocasiones, los productos frescos exigen procesos de producción, recolección, selección, clasificación, control de calidad, conservación y transporte bastante complejos. Los mercados de consumo final de estos productos tienden a ser exigentes en materia de calidad y presentación, por lo que son necesarios diversos servicios anexos al proceso productivo que incrementan el valor agregado y la incorporación de conocimiento tecnológico (CEPAL, 1993a).

La aparición de productos más dinámicos, menos vulnerables y con mayor incorporación de conocimiento y tecnología, por lo general no es un resultado automático del mercado. En algunos casos se requieren señales precisas de consolidación de liderazgos nacionales, y en otros alianzas público-privadas en la promoción externa para capturar posiciones de mercado, buscando una aplicación focalizada de los instrumentos de fomento productivo y exportador.

Existe allí campo para los consensos con miras al desarrollo sectorial. En efecto, si sectores emergentes, con dinamismo ya validado por el mercado y un volumen alto de exportaciones, enfrentan ciertas insuficiencias en comercialización, capacitación, diseño, tecnología o infraestructura, es posible articular esfuerzos públicos y privados para focalizar allí los instrumentos horizontales existentes. Por otra parte, se puede minimizar las posibilidades de cabildeo si existen instituciones públicas no estatales integradas por agrupaciones empresariales (incluidas las exportadoras), así como centros tecnológicos y académicos, que funcionen con elevada transparencia en la asignación de fondos y en la evaluación y seguimiento de las actividades.

\footnotetext{
6 Las importaciones de la OCDE en 1978-1987 crecieron a una tasa anual de $5.7 \%$. Los productos con mayor contenido de recursos naturales crecieron menos que eso y los que incorporaban más conocimiento lo hicieron a más de 10 ó $15 \%$. Por ejemplo, las importaciones de madera crecieron menos de $1 \%$ por año y las manufacturas de maderas $9 \%$. Esto da fuerza al argumento de que es necesario potenciar redes de producción en torno a recursos naturales existentes.
} 
El sector público no está mejor capacitado que el privado para escoger "ganadores", pero sí tiene ventajas -o puede construirlas - para la coordinación de esfuerzos y el estímulo de visiones prospectivas de la economía internacional y de los mercados pertinentes. El sector público podría escuchar las demandas de los empresarios y de los inversores extranjeros a la hora de definir sus gastos en infraestructura y recursos humanos y sus políticas de financiamiento de largo plazo, a fin de maximizar su efecto en la competitividad sistémica y la difusión tecnológica.

Como expresión institucional puede sugerirse la gestación de centros de productividad y competitividad de carácter tripartito, es decir, con participación del sector público — gobierno, universidades, centros tecnológicos-, de organizaciones empresariales y de organizaciones de trabajadores, que hagan el seguimiento de la evolución de la competitividad y de las tendencias tecnológicas y comerciales de carácter sectorial, abordando las temáticas nacionales con una adecuada incorporación de los aspectos internacionales involucrados. Esta práctica reforzaría los comportamientos de economía global, abierta al mundo, estimulando relaciones de cooperación entre los agentes económicos.

\section{IV}

\section{Internacionalización y énfasis exportador}

En la actualidad, la actividad productiva y por cierto la exportadora responden a un concepto de redes. El negocio exportador constituye una red o circuito integrado que incluye diversos eslabones: proveedores, producción, transporte, importación, distribución, comercialización, financiamiento al importador y al cliente, servicios legales y financieros, etc. La competitividad de un producto dependerá de la eficiencia de cada uno de estos eslabones.

Surgen aquí dos consideraciones de política: en primer lugar, es importante fomentar la articulación de estos eslabonamientos productivos y de servicios, estimulando la especialización y externalización de funciones a través de alianzas estratégicas con proveedores, con cadenas de comercialización y transporte, con los consumidores e incluso con los competidores; en segundo lugar, es necesario reexaminar la pertinencia de los incentivos para exportar a fin de tener en cuenta la importancia de las cadenas de exportación.

Desde este punto de vista, el objetivo es apoyar a todas las empresas que tengan potencial competitivo, cualquiera sea su tamaño, focalizando el apoyo público en la eliminación de las trabas específicas que limitan el despliegue de ese potencial y fortaleciendo los eslabones dinámicos. Por otra parte, el apoyo a las pequeñas y medianas empresas, más que tender a desarrollarlas como compartimientos estancos, a veces "protegidos", debiera orientarse a crear y fortalecer sus vínculos con empresas exitosas de mayor tamaño y facilitar su inserción en cadenas de exportación, actuando inicialmente como subcontratistas o exportadores indirectos. Lo central en cada caso es seguir de cerca el comportamiento competitivo de los principales rubros de exportación, para descubrir trabas y oportunidades y reaccionar oportunamente frente a ellas, en la medida de los recursos y en función de políticas no discriminatorias.

La calidad de la especialización internacional no es sólo una preocupación comercial. Repercute directamente en las posibilidades de generar empleo productivo y salarios crecientes. Especializarse en productos de bajo crecimiento, con marcados ciclos de precios y sujetos a prácticas proteccionistas puede llegar a afectar los equilibrios macroeconómicos; por otro lado, apoyarse excesivamente en recursos naturales de poca elaboración, en salarios bajos o en insuficientes condiciones laborales dificulta una competitividad sistémica.

Para avanzar en la internacionalización productiva conviene estrechar la colaboración entre el sector público y el privado. Ello es necesario, por ejemplo, para favorecer una mayor influencia nacional en las cadenas globales de producción, comercialización y transporte que están ligadas a la oferta exportable, y para estimular la conformación de empresas comercializadoras nacionales, como parte de una política comercial más activa y de una coordinación públicoprivada más estrecha.

El aporte fundamental del sector público al des- 
empeño exportador radica en: i) garantizar un ambiente de crecimiento y estabilidad económica; ii) gestar una orientación global de los incentivos que reduzca los sesgos antiexportadores y garantice el acceso a insumos en condiciones competitivas, y iii) dar apoyo institucional a la actividad exportadora, particularmente en materia de información, financiamiento, seguro de exportación y promoción de la oferta exportable en el exterior. ${ }^{7}$

Lo anterior, sin embargo, no basta para avanzar hacia una fase de internacionalización productiva y profundización exportadora. Por lo tanto, es necesario acompañar ese aporte con inversión en el exterior, participación en cadenas de comercialización, operaciones conjuntas con empresas del país en los mercados de destino, y dar nuevo relieve a los aspectos de promoción, calidad y diferenciación de marca.

La experiencia de las economías asiáticas muestra la importancia estratégica de estas áreas, en particular: i) la creación de empresas comercializadorasexportadoras; ii) la instalación en los principales mercados de destino de empresas importadoras de productos nacionales; iii) la suscripción de contratos de exportación, con incentivos diferenciados de conformidad con compromisos sobre el valor exportado, y iv) la promoción de la inversión en el exterior para la comercialización y la participación en cadenas mayoristas de distribución. Todos estos aspectos son cada vez más relevantes para la internacionalización productiva y el aumento de la competitividad (Rosales, 1994; CEPAL, 1994a).

El sector público podría colaborar en estas tareas, particularmente durante períodos macroeconómicos en que importantes ingresos de divisas a la economía tienden a depreciar el tipo de cambio real y desalentar las exportaciones. En aquellos casos se podría evaluar la posibilidad de aplicar montos reducidos y acotados de las reservas internacionales (1\% de ellas) a estas iniciativas de promoción externa, sujeta al aporte de montos similares por las agrupaciones exportadoras. Tales recursos se podrían asignar a proyectos de oficinas comerciales en el exterior o a gastos de promoción que otorguen beneficios a todos los exportadores. Cabe señalar que los países asiáticos premian con doble deducción tributaria los gastos de las empresas en promoción en el exterior y en tecnología (anexo 1).

\footnotetext{
7 En CEPAL (1994a, cap. V) se pasa revista a los incentivos fiscales y financieros para la promoción de las exportaciones de América Latina.
}

Algunos aspectos destacados en la profundización exportadora ${ }^{8}$ son los siguientes:

i) Estimular las empresas comercializadoras nacionales, como parte de un esfuerzo de política comercial más activa, y mejorar la propia organización de los exportadores, son otras tareas para la fase de profundización exportadora. Respecto de algunos productos agrícolas y del mar, por ejemplo, parece haberse inaugurado una etapa de mayores requerimientos en materia de calidad, estandarización, promoción comercial, alianzas con importadores y coordinación de la oferta, ya que el mercado es más exigente y hay nuevos competidores. Es preciso entonces organizarse para exportar mejor, mejorando la gestión privada de promoción y comercialización y aprendiendo de las experiencias satisfactorias. ${ }^{9}$

ii) El financiamiento competitivo para exportadores no tradicionales o pioneros seguirá siendo un eje importante de la promoción exportadora. Extender el seguro de exportación (o crearlo cuando no existe), gestar líneas de financiamiento de largo plazo para exportadores de manufacturas y servicios en condiciones internacionalmente competitivas y crear los mecanismos e incentivos necesarios para incorporar a la banca privada a este rubro, son requisitos previos indispensables para la profundización exportadora.

iii) En materia de promoción comercial, es necesario superar la acción atomizada, individual y a veces ingenua, incompatible tanto con la gravitación de las exportaciones en economías que han optado por una mayor integración a los mercados internacionales, como con la penetración que algunas de ellas han alcanzado en mercados sofisticados. En este ámbito, es preciso aumentar los recursos públicos dedicados a promoción; establecer incentivos que favorezcan la promoción comercial; conseguir que el sector privado invierta más en esta tarea, y

\footnotetext{
${ }^{8}$ En este artículo, el concepto de profundización exportadora abarca: diversificación de productos y mercados; incorporación de conocimiento y tecnología; creación de cadenas de exportación; mayor incorporación de la pequeña y mediana empresa, e instauración de estímulos para mejorar la calidad de los productos.

${ }^{9}$ Entre los casos más destacados de exportaciones no tradicionales ligadas a recursos naturales se encuentran las de crustáceos y moluscos frescos (Argentina y Panamá), harinas solubles y alimentos similares para animales derivados de especies marinas (Chile y Ecuador), camarones congelados (Ecuador), salmones (Chile), uva (Chile y México), manzanas (Chile), piñas (Costa Rica y la República Dominicana), jugo concentrado de naranja (Brasil), carne fresca de pollo (México), flores cortadas (Colombia y Costa Rica), madera aserrada y traviesas (Chile). Véase CEPAL, 1993a.
} 
mejorar la coordinación público-privada, entre otras cosas, en la promoción de la imagen del país respectivo.

iv) El carácter promocional de la política de inversión extranjera puede traducirse también en una política más activa de alianzas estratégicas con empresas transnacionales, y de estímulo a la inversión extranjera en manufacturas, servicios y formación de recursos humanos, a través de señales más precisas de diversificación sectorial. Facilitar dicha inversión mediante la reducción de los tributos a la transferencia tecnológica, los servicios y la asistencia técnica, y los acuerdos bilaterales que eviten la doble tributación, es un camino que puede ser ventajoso, particularmente en aquellas economías más avanzadas en las reformas estructurales.

v) Mejorar la coordinación y pertinencia en el diseño, aplicación y evaluación de las medidas de fomento a las exportaciones que corresponden a la devolución de impuestos y derechos aduaneros, generalmente es tarea que compete a diversos organismos públicos (aduanas, impuestos internos, tesorería y ministerios de economía, comercio exterior o industria), lo que dificulta a veces la coordinación e impone costos evitables a los exportadores. Areas tan importantes como la importación y exportación de servicios y el financiamiento de las actividades exportadoras a veces no encuentran una clara contraparte institucional. Para desburocratizar los trámites de comercio exterior es preciso mejorar el manejo de la información y el registro de las exportaciones e importaciones, haciendo uso de la informática, y marchar hacia una ventanilla única para los exportadores y para sus relaciones con el servicio de aduanas. ${ }^{10}$

Hay aquí un desafío permanente de reducción del sesgo antiexportador: el de readecuar normas, flexibilizar procedimientos, reducir trámites y burocracia y tecnificar al personal.

vi) Un ámbito poco desarrollado en la región y que empieza a adquirir importancia es la vigilancia de las prácticas de competencia desleal en el comercio exterior. ${ }^{11}$ Especial atención en los acuerdos comerciales, por ejemplo, están recibiendo el tratamiento de las inversiones, los servicios, las medidas antidumping, las cláusulas de salvaguarda y los mecanismos para la solución de controversias. La gestión de tal sistema requiere: i) estar radicada en instancias que garanticen el conocimiento de las realidades sectoriales; ii) un estrecho contacto con el sector privado, y iii) un alto grado de tecnificación y credibilidad, de modo de evitar su utilización por intereses particulares con objetivos proteccionistas.

Las instituciones públicas destinadas al diseño y ejecución de las políticas de desarrollo exportador no han evolucionado a parejas con la intensidad creciente del proceso de internacionalización de las economías de la región. De allí el interés por readecuar los ritmos y desempeños de los organismos de promoción y de las respectivas cancillerías a estos nuevos desafíos. Tal readecuación debería realizarse de consuno con las organizaciones de exportadores, estimulando un mayor compromiso privado con las políticas de promoción comercial, fomento tecnológico y capacitación.

vii) La modernización de la gestión e institucionalidad de la política económica internacional desempeña un papel decisivo en los esfuerzos de internacionalización.

Se trata de unificar los criterios económicos y políticos, de otorgar mayor peso al componente económico de las relaciones internacionales y de mejorar el apoyo político y técnico a las tareas de las relaciones económicas internacionales. Ayudaría para tales propósitos perfilar estrategias nacionales de carácter consensual, con expresiones definidas de promoción del comercio y de las inversiones por regiones y por megamercados, lo que permitiría un manejo unificado y oportuno de las tareas de promoción comercial, conquista y defensa de mercados y prospección de novedades tecnológicas y oportunidades de negocios.
10 El avance de la actividad exportadora va planteando nuevos desafíos. Así, por ejemplo, la gestión de los puertos debe irse adaptando a prácticas de transporte multimodal, incorporando cambios tecnológicos, como el uso de contenedores y el intercambio electrónico de datos (CEPAL, 1993b).

\footnotetext{
11 La nueva Ley de Comercio Exterior de México, publicada en el Diario Oficial el 27 de julio de 1993, incluye normas precisas sobre discriminación de precios, subvenciones, daño y amenaza de daño a la producción nacional, medidas de salvaguarda y procedimientos (Banco Nacional de Comercio Exterior, 1993).
} 


\section{V}

\section{Dimensiones de las políticas de fomento} productivo

El debate actual en la región sobre políticas industriales (o mejor, sobre fomento de la competitividad) gira principalmente en torno a requisitos técnicos y de economía política.

Por el lado de los requisitos técnicos, tales políticas i) tienden a apoyarse en instituciones de mercado; ii) privilegian la eficiencia dinámica de la competitividad; iii) recurren a incentivos acotados en el tiempo, decrecientes y autodesmontables, ligados a metas precisas de exportación; iv) tienen metas reducidas y concentran la masa crítica del sector público en programas de impacto decisivo, en función de la capacidad técnica y administrativa de éste; v) propician la descentralización de la administración y seguimiento de los incentivos, y vi) concentran la selectividad en exportaciones pioneras o con alto contenido de conocimiento.

Por el lado de los requisitos de economía política, las políticas de fomento productivo han de ser políticas públicas (y no estatales), y consensuales (antes que tecnocrático-administrativas). Un contraargumento ortodoxo señala que la irrupción de la información en sus dimensiones actuales descarta cualquier posibilidad de establecer prioridades productivas, pues no existe instancia pública capaz de acumular y procesar oportunamente flujos tales de información.

En verdad, lo anterior es aplicable a cualquier instancia, pública o privada. El gran espacio para la acción pública aquí es el de compartir información, llegar a diagnósticos consensuales y generar una institucionalidad para el desarrollo flexible, informado y concertado, que reduzca la incertidumbre. ${ }^{12}$ La principal ventaja competitiva del sector público es la posibilidad de favorecer este proceso públicoprivado de información compartida, y propiciar diagnósticos consensuales y una gama de instrumen-

\footnotetext{
12 Paradójicamente, la imposibilidad pública de procesar eficazmente la información tecnológica, comercial y financiera para in ducir opciones productivas puede transformarse en una ventaja, si se acude a prácticas de concertación de los actores, institucionalizando la interlocución, la negociación y las visiones prospectivas del entorno internacional.
}

tos para el seguimiento, la evaluación y la corrección de los procesos de inversión, exportación, capacitación, desarrollo de infraestructura y difusión tecnológica.

\section{Políticas horizontales y de mercado}

El actual fomento productivo tiene una dimensión horizontal -es decir, no apoya a sectores o actividades específicas- y otra factorial, con beneficios que se difunden transversalmente a diversas ramas, apoyando la gestación de mercados y redes institucionales que faciliten el desarrollo de los factores de producción.

El fomento productivo se entiende entonces apoyado en instrumentos horizontales que mejoren la coordinación dentro del sector privado y entre éste y el sector público, y que reduzcan el riesgo asociado a nuevas inversiones, mejorando la información y el acceso flexible a los instrumentos existentes.

El consenso respecto de políticas industriales se traduce en políticas que no interfieren con el mercado y que intentan mejorar su funcionamiento, fortaleciéndolo o corrigiéndolo, según corresponda. Es una visión de ajuste positivo, basada en principios de mercado y de competencia, que asigna la responsabilidad del ajuste estructural a las empresas. Concentra la tarea pública en garantizar un ambiente adecuado para la inversión privada, el crecimiento estable, el predominio de la competencia y el acceso a los mercados.

Cuando se examinan las estrategias de especialización comercial, ya no basta con diferenciar entre estrategias tomadoras de precios (price-takers) y las que fijan precios (price-makers); la verdadera diferencia se da hoy entre las estrategias pasivas (de aceptación de factores) y activas (de creación de factores). Allí radica la distinción analítica entre "ventajas comparativas" y "ventajas competitivas" (nacionalmente construidas).

Avanzar en materia de competitividad es construir entonces factores y ventajas competitivas. Dadas las características de la competitividad actual, esto 
apunta a políticas de naturaleza horizontal, que no discriminen entre actividades ni entre empresas; que se dirijan expresamente a resolver una insuficiencia conocida del mercado, a impulsar una industria o región en general o a promover el desarrollo de insumos críticos para la competitividad sistémica, como la capacitación y la infraestructura (OCDE, 1992).

\section{Promoción de la competencia}

El funcionamiento competitivo de los mercados constituye un eje de la política industrial. A su vez, la promoción de la competencia requiere un adecuado marco regulador.

Para apoyarse en las potencialidades del mercado es preciso contar con mercados competitivos, transparentes y de acceso fluido. Crear mercados donde no existan, fortalecerlos donde admitan mejoras y regularlos cuando son críticos, son elementos de una política industrial promercado. Democratizar el acceso a los mercados, mejorar su eficiencia y transparencia, y reducir las tendencias a la concentración económica, es además la forma moderna de elevar la eficiencia, la competitividad y la equidad. ${ }^{13}$

Para asegurar la operación efectiva de mercados competitivos se necesita un sector público con suficiente capacidad reguladora para actuar tanto sobre la estructura de los mercados, evitando prácticas no competitivas, como sobre los resultados de su operación. En general, promover la competencia es la mejor política para estimular la eficiencia; sin embargo, cuando ello no sea posible, la regulación oportuna es la segunda alternativa. En buena parte de los países de la región es necesario mejorar la institucionalidad que regula los mercados financiero, previsional, de la energía, de los recursos naturales no renovables y de los servicios de utilidad pública, así como dar adecuada ubicación institucional a la vigilancia de la competencia desleal.

El marco institucional de la regulación de la competencia debe incluir medidas que fortalezcan la disciplina de mercado, refuercen la movilidad de los recursos y mejoren su disponibilidad (Atiyas,

\footnotetext{
13 Completar los mercados de tecnología; facilitar el acceso de los trabajadores al mercado de capacitación; superar las segmentaciones del mercado de capitales, mejorando el acceso al crédito de las pequeñas y medianas industrias, $y$ mejorar las relaciones contractuales entre contratistas y proveedores y entre exportadores directos e indirectos, son formas de promover el mercado que, junto con favorecer la competitividad, repercuten favorablemente en la equidad.
}

Dutz y Frischtak, 1992; Tavares de Araújo Jr., 1993).

La disciplina de mercado se fortalece con menor protección, políticas antimonopolios, regulación y supervisión de instituciones financieras, privatizaciones, contratos de desempeño en las empresas públicas y resguardo al consumidor y a los pequeños accionistas.

La movilidad de los recursos se estimula con medidas que eliminen las barreras de entrada y salida, flexibilicen los mercados, reduzcan los costos de transacción, mejoren el acceso a la información, y remuevan regulaciones que dificultan las transferencias de activos (leyes de quiebra, reformas a la justicia). En el caso del mercado del trabajo, tal movilidad se facilita mejorando la información y favoreciendo la flexibilidad, entre otras cosas, con seguros de desempleo, jornadas flexibles y salarios participativos. ${ }^{14}$

La disponibilidad de recursos mejora junto con el incremento de las corrientes financieras y de información. Aquí intervienen programas de capacitación laboral y empresarial, de difusión tecnológica, y de promoción de la afluencia de tecnología y de inversión extranjera. Operan favorablemente también la fluidez de las reestructuraciones financieras en caso de fracasos, la acción de organismos especializados en la reconversión de activos y las políticas que faciliten la intermediación financiera y la profundización del mercado de capitales, particularmente para abarcar las empresas pequeñas y medianas, las nuevas empresas y las inversiones tecnológicas.

\section{Criterios de reconversión productiva}

El principal objetivo de la reconversión productiva y ocupacional es facilitar el ajuste con mecanismos de mercado que permitan recuperar competitividad o generarla en actividades distintas. Esto implica propiciar el traslado desde empleos de baja productividad a otros de productividad mayor, con reasignaciones intersectoriales o intrasectoriales, subsidios específicos, programas de capacitación, rebajas tributarias para invertir en la región y otros medios. Lo que no puede

\footnotetext{
14 La modalidad de salarios participativos refuerza el vínculo entre salarios y productividad, al remunerar el trabajo según rendimiento; inhibe el despido y estimula la contratación, al flexibilizar el costo de la mano de obra; y al identificar las remuneraciones con los resultados de la empresa, suele mejorar el clima de relaciones laborales (CEPAL, 1992a, cap. VI).
} 
hacer la política industrial es frenar o retardar el proceso de reconversión.

En períodos de globalización, la reconversión forma parte de la estrategia de inserción internacional y de desarrollo productivo, ya que se debe complementar el fomento de sectores dinámicos con la reconversión de sectores rezagados. Será necesario ir creando anticipadamente una capacidad de reconversión concertada en sectores o regiones cuya competitividad esté amenazada; las medidas que se tomen deberán facilitar la reasignación de recursos hacia actividades con mayor futuro, cuidando de minimizar el costo social de esa reasignación, y de preservar, modernizar y reorientar capacidades laborales y empresariales.

Aunque las políticas horizontales constituyen un marco necesario, no parecen suficientes para atender a las especificidades sectoriales y regionales cuando concurren regiones o sectores con acentuado rezago competitivo o, peor aún, con daño estructural.

Las experiencias de ajuste estructural más avanzadas muestran casos exitosos de inserción internacional a través de políticas sectoriales (en México, el sector de vehículos automotores y el de computación), y también casos de aparición de dificultades sectoriales y regionales (en Chile, el sector textil y el del carbón en la VIII Región), que muestran un cierto agotamiento de las políticas horizontales para abordar tales problemas.

La reconversión como política pública tiende a ser inevitable cuando sectores o regiones de importancia económica y social sufren persistentes e importantes rezagos competitivos. Si estos sectores cuentan con capacidad para recuperarse, pero no encuentran en el mercado ni en el instrumental de fomento en vigor un estímulo suficiente para hacerlo por sí mismos, el sector público puede complementar los esfuerzos de readecuación competitiva. Cuando tales sectores no cuentan con capacidad para recuperarse, de lo que en verdad se trata es de minimizar el costo social de retirarse del sector.

En los casos de reconversión es necesario focalizar el acervo de políticas horizontales, de manera de brindar apoyo coordinado a sectores o regiones rezagados en competitividad. Tales políticas apuntan a perfeccionar los mercados de factores, ampliar la oferta de externalidades para la producción, mejorar el acceso a la información comercial y tecnológica, al financiamiento y al apoyo tecnológico, y reducir los costos de transacción. Es recomendable entonces que las medidas de apoyo financiero, fomento tecnológico, asistencia técnica, capacitación, reconversión laboral y seguro de desempleo estén integradas, y que mantengan un vínculo estrecho con las políticas sociales y su expresión territorial y local.

De este modo, cuando se trata de reconversión, las políticas horizontales o factoriales (en materia de tecnología, capacitación, fomento exportador, infraestructura) pueden tener destino sectorial. Tales casos pueden abordarse con programas públicos excepcionales, específicos y focalizados, de duración temporal definida, que articulen de manera flexible y consensual los esfuerzos de los sectores público y privado.

Es posible que diagnósticos más afinados aconsejen cambios intrasectoriales, racionalizaciones menores o modernizaciones, que requieren recursos públicos. Lo primero, en todo caso, es separar el rezago competitivo de la declinación estructural. Lo segundo es separar la empresa o actividad de la región afectada. Con lo primero se estará diferenciando entre políticas de recuperación competitiva y otras de salida del sector; con lo segundo se estará diferenciando la política de fomento productivo de las políticas de desarrollo regional. En otras palabras, reducir el costo social de la pérdida de competitividad de alguna empresa importante de una región no significa necesariamente rescatar tal empresa a cualquier costo.

\section{Un trato unificado}

La competitividad emergente privilegia el componente sistémico; no es eficiente entonces que las políticas de fomento competitivo se diseñen y gestionen como compartimientos estancos, desaprovechando las obvias interrelaciones sectoriales, regionales e institucionales presentes en el accionar público. En tal sentido, coordinar las políticas de inversión pública, de infraestructura, de formación de recursos humanos, de incentivos a la exportación, de apoyo tecnológico y financiero y de cooperación técnica, es de la mayor prioridad. Tal coordinación debiera expresarse en algún referente institucional, al que sea posible evaluar en su gestión unificada de estas políticas. De paso, tal gestión unificada reduce la demanda de recursos financieros adicionales, puesto que la coherencia de la acción en diversos ámbitos públicos genera externalidades y claras economías de escala que facilitan la focalización del esfuerzo administrativo y de la asignación de recursos.

El énfasis en mejorar la competitividad es el que exige esta mayor coordinación de las políticas de fomento productivo, estrechando el vínculo entre ellas 
y la política comercial. En efecto, el fomento productivo en economías abiertas está ligado a la reducción de los sesgos contra la exportación, a la promoción global de las exportaciones y a la promoción selectiva de exportaciones pioneras o con alto contenido de conocimiento. Por otra parte, la mayor exposición de la economía interna a las importaciones está obligando a los países de la región a prestar más atención a los temas de reconversión productiva y de tratamiento de la competencia desleal. Finalmente, la necesidad de avanzar en la internacionalización de las economías está planteando desafíos de tecnificación y actualización en las relaciones económicas internacionales. Ciertamente las opciones de apoyo productivo no podrían estar desligadas de los avances en el conjunto de estos campos.

El trato unificado de las políticas de desarrollo productivo surge también como corolario de las polí- ticas de transformación productiva que buscan dar ese mismo trato a los temas económicos y sociales. En la medida en que la reducción de la pobreza y el avance hacia la igualdad de oportunidades radican en el crecimiento económico, en la modernización productiva y en la generación de más y mejores empleos productivos, es claro que para profundizar los avances distributivos ${ }^{15}$ se necesitarán mejoras complementarias en la eficiencia de la gestión macroeconómica $^{16}$ y en la capacidad competitiva. Así, la gradual transformación productiva debiera irse reflejando en una política económica que otorgue creciente importancia a las políticas de fomento productivo. En la sección siguiente se describen brevemente cuatro áreas que se privilegian en este ámbito: productividad (haciendo hincapié en la innovación y la calidad), fomento y difusión tecnológica, capacitación y políticas de infraestructura.

\section{VI}

\section{Fomento de la competitividad}

\section{Productividad: innovación y calidad}

Los incrementos de productividad están ligados a la innovación, al fomento tecnológico y a la mejora de la calidad. Flexibilizar horarios, contratos y actividades, por ejemplo, puede ser un aspecto clave de la productividad, particularmente en la eliminación de tareas redundantes, de procesos que se mantienen por inercia o de legislaciones que no se han adaptado a las nuevas realidades..$^{17} \mathrm{La}$ legislación laboral, por

15 En materia de política social, esto involucra ampliar su cobertura y mejorar su eficacia; fortalecer el vínculo con las políticas de desarrollo productivo, haciendo hincapié en la inversión en las personas de modo de mejorar su capacidad de acceso a empleo productivo, y proteger a los grupos más vulnerables. Todo ello con financiamientos compatibles con los equilibros macroeconómicos.

16 Para tales avances, además de los aspectos tradicionales es preciso incorporar el de la regulación, cuyo propósito principal es lograr que los mercados funcionen con mayor eficiencia y sean más transparentes, disminuyendo así la posibilidad de concentración económica y abriendo a todos la posibilidad de acceder a ellos.

17 Pese a que las economías de la región han virado desde modelos de economía cerrada hacia estrategias de economía abierta y de inserción internacional, existe un conjunto amplio de leyes y normas de economía cerrada que persisten, entrabando el accionar innovador de los sectores público y privado. Lo propio acontece con los procesos de desregulación y privatización de algunos servicios pú- ejemplo, debiera ser readecuada, abriendo espacio a la innovación y a la concertación en la empresa. Una sugerencia importante al respecto es la ya comentada de "salarios participativos" (CEPAL, 1992a).

\section{a) Innovación}

Las distintas visiones del cambio tecnológico y de las relaciones laborales concuerdan en que el principal obstáculo a la innovación es la existencia de relaciones no cooperativas dentro de la empresa. Del mismo modo, destacan la necesidad de contar con una fuerza de trabajo calificada, flexible y motivada, como insumo esencial de la innovación tecnológica. Señalan además que la mayor parte del cambio tecnológico es incremental, es decir, marginal y cotidiana, y se da en la interacción del proceso productivo. Esto refuerza la necesidad de empresas que funcionen en un clima de cooperación y que estén abiertas a la participación y a la innovación, un rasgo cada vez más crucial del desempeño competitivo.

Actualmente se piensa que las relaciones de baja cooperación entre individuos y organizaciones actúan

blicos, los que no han sido acompañados por modificaciones funcionales en la legislación. 
como vallas a la innovación tecnológica y al mejoramiento del desempeño industrial (Solow, Dertouzos y Lester, 1989). Más aún, la cooperación entre competidores es parte de las nuevas reglas y elemento esencial del desempeño innovador. (Como ejemplos de industrias cooperativas pueden mencionarse las de máquinas herramientas de Módena, la industria textil italiana, la de muebles danesa y la propia industria alemana, descrita alguna vez como un "grupo de clubes") (Jorde y Teece, 1990).

El modelo tradicional de innovąción tecnológica la concebía como un proceso lineal y predecible, que iba desde la investigación al desarrollo, diseño y producción, y luego a la comercialización, ventas y servicio. Este modelo recogía la experiencia de industrias a gran escala, pero no la sinergia de las innovaciones acumulativas, eje del actual cambio tecnológico (especialmente en semiconductores, computadores y automóviles).

En la actualidad, la innovación tecnológica se concibe como un proceso sistémico de descubrimiento, desarrollo, mejoramiento, adopción y comercialización de nuevos procesos, productos, procedimientos y estructuras organizacionales (Jorde y Teece, 1990). Se la concibe también como un proceso que se puede estimular, fortaleciendo los vínculos y mecanismos de retroalimentación dentro de la empresa, entre empresas, y entre centros tecnológicos y universidades. Así, la innovación deja de ser un proceso serial y ni siquiera empieza con la investigación, ya que el nuevo funcionamiento de las empresas en un contexto global obliga a privilegiar el vínculo con los consumidores $\mathrm{y}$, por lo tanto, a innovar a partir de los servicios posventa.

\section{b) Calidad}

Las crecientes exigencias de calidad en los mercados internacionales están haciendo que los países de la región concedan creciente importancia al tema, y lo incorporen en las políticas de fomento productivo y exportador. En efecto, los incentivos a la calidad pueden favorecer aumentos de productividad y una gradual adecuación a estándares internacionales más estrictos.

La instauración de sistemas de calidad en las empresas permite modernizar las técnicas de gestión $y$, particularmente en las pequeñas y medianas, racionalizar costos y aprovechar mejor los incentivos disponibles, muchas veces inutilizados por desconocimiento o por insuficiencias en la gestión empresarial. De otra parte, estimular la gestación de empresas pri- vadas que se especialicen en la certificación de calidad favorece la competencia y permite que el sector público pueda concentrarse en las normas de regulación y supervisión; mayor competencia en ese crucial mercado permite al sector público contar con más opciones a la hora de definir laboratorios de referencia.

Los canales internacionales de distribución movilizan bienes y servicios destinados a consumidores exigentes. De allí que crear consumidores internos exigentes forma parte de las políticas de promoción de calidad, las que debieran apuntar a superar las diferencias, a veces muy marcadas, entre la calidad para exportar y la calidad para el mercado interno. La legislación sobre la calidad de los bienes y servicios y la protección al consumidor constituyen entonces parte del fomento de la calidad y la competitividad.

\section{Fomento y difusión tecnológica}

El mercado suministra una dotación subóptima de información y de oferta tecnológica (Stiglitz, 1989). En campos como la tecnología y la información, esenciales para la modernización productiva, las externalidades suelen ser determinantes. El uso privado de la tecnología y la información no agota su disponibilidad para otros agentes (Romer, 1992); con ello, los beneficios sociales superan a los privados y se justifica entonces una acción pública tendiente a generar mayor actividad de investigación y desarrollo tecnológico que la que determinaría el mercado por sí sólo.

"Completar" los mercados de tecnología es entonces una típica tarea pública, dadas las externalidades envueltas. Para ello es necesario robustecer la demanda, y el vínculo entre ésta y la oferta, favoreciendo el acceso de agentes pequeños y medianos a la información y a la tecnología.

La oferta de tecnología no representa una restricción para el incremento de la productividad y la innovación tecnológica. El real obstáculo es la falta de demanda de las empresas en este campo, derivada de una imperfecta información en los mercados de tecnología (Peres, 1993).

Los mecanismos tendientes a desarrollar la oferta tecnológica deben atender tanto a la oferta pública como a la privada. En el fomento de la oferta privada conviene hacer hincapié en el desarrollo a nivel de empresa y en promover vínculos más estrechos entre empresas y centros tecnológicos. Un instrumento apropiado para ello puede ser el de incentivar contra- 
tos de investigación para innovar y adaptar tecnologías, incrementando así los fondos privados para actividades de investigación y desarrollo tecnológico y favoreciéndolos con deducciones tributarias para proyectos propios o para aportes privados a centros tecnológicos.

En lo referente a la oferta tecnológica pública hoy se apunta sobre todo a vincular más los recursos a resultados evaluables, de conformidad con indicadores de desempeño. Para reforzar esta orientación es conveniente incrementar la participación privada en la gestión y en el financiamiento de los institutos tecnológicos públicos y, como contrapartida, flexibilizar la gestión presupuestaria de esos institutos, así como las reglas de operación, los montos y los tipos de proyectos aceptables en los programas de apoyo a la innovación tecnológica.

En general, los recursos asignados a los institutos tecnológicos del sector público corresponden al mayor gasto en tecnología que se realiza en los países de la región. Sin embargo, en buena medida ese significativo monto de recursos no está sujeto a evaluaciones periódicas de rendimiento. Por lo tanto, el paso del actual financiamiento casi garantizado de la oferta pública de tecnología hacia una mayor competencia por los fondos a base de proyectos evaluables, debiera reflejarse en una mayor rentabilidad social de esos recursos, en un mayor dinamismo de la base productiva y en más contacto de dichos institutos con ella.

Considerando las características de la competitividad reseñadas antes, tales programas debieran apoyar, entre otras cosas, el escalamiento de las innovaciones, las alianzas productivas y tecnológicas, las operaciones de subcontratación, las cadenas productivas, las empresas tecnológicas, y la adaptación y difusión tecnológicas.

Por el lado de la demanda, las medidas deben orientarse a inducir una demanda inicial de las empresas y a acompañar su progresiva sofisticación. La experiencia internacional muestra que la extensión industrial desempeña un papel central como inductor de demanda. El sector público puede asumir esta tarea mientras el mercado tecnológico no alcance su madurez, densificando las redes de contactos entre agentes tecnológicos. Una vez que determinadas empresas generen su propia demanda y requieran apoyo en el exterior, el sector público debiera acompañar tal esfuerzo con la inclusión de los temas tecnológicos como elemento importante de la política económica.
Junto con dar esa relevancia a la tecnología debe hacerse una focalización de objetivos altamente selectiva, a modo de efecto de demostración. El avance tecnológico supone concentrar esfuerzos en áreas específicas, dando a través de las políticas públicas señales expresas de prioridades tecnológicas y articulando esfuerzos e instituciones tras una efectiva movilización tecnológica de los agentes económicos.

Las prioridades pueden emanar de un esfuerzo mancomunado público-privado de diálogo, información compartida, diagnóstico consensual y división complementaria de tareas, atendiendo a las ventajas comparativas de cada agente. La difusión y la extensión deberán ocupar el centro de las actividades tecnológicas y realizarse a través de una estrecha cooperación entre el sector público y el privado, y entre empresas, universidades y centros tecnológicos, fomentando la creación o desarrollo de entes de difusión y demostración tecnológica.

Para colocar la difusión tecnológica entre las urgencias nacionales, la CEPAL viene promoviendo la idea de visitas tripartitas a plantas en el exterior que aplican la mejor práctica tecnológica. En tales visitas participarían empresarios, técnicos, obreros y dirigentes sindicales de varias empresas de los diversos subsectores productivos. A su vuelta, deberían preparar informes detallados sobre los procesos de producción, equipos, sistemas de control de calidad y relaciones industriales que hayan observado en las plantas visitadas, y sobre las posibilidades de aplicarlos en sus empresas. Tales resultados serían difundidos a las organizaciones empresariales y laborales, con miras a hacer de la productividad y la innovación una preocupación principal de trabajadores, sindicatos y empresarios (CEPAL, 1994a).

Con medidas como las descritas, de bajo costo y orientadas a articular los esfuerzos de los actores del proceso productivo, sería posible consolidar o diseñar instrumentos y mecanismos para hacer que el gasto del sector privado en tecnología aumente con más rapidez que el del sector público. Con todo, para maximizar la eficacia del gasto público en esta área, convendría que los recursos para instituciones tecnologicas públicas, ya sea aportes directos o fondos que se obtienen por concurso, estén ligados a indicadores de desempeño, y que su manejo administrativo sea más flexible y más fácil de evaluar.

A modo de síntesis se señala un conjunto de acciones que pueden desarrollarse en el marco de una política de fomento tecnológico: 
i) Perfilar prioridades públicas en ciencia y tecnología, con participación de la comunidad científica y tecnológica y de las organizaciones empresariales.

ii) Dotar de institucionalidad y rango jerárquico a la transferencia, adaptación, copia, difusión e innovación de tecnologías.

iii) Mejorar la articulación entre oferta y demanda de tecnología; dar mayor difusión a la información tecnológica y comercial; apoyar la conformación de mercados regionales de tecnología y de trabajo calificado.

iv) Aumentar el gasto público en investigación y desarrollo, con criterios de eficiencia y desempeño y estimular el privado con incentivos tributarios.

v) Estimular sistemas de capital de riesgo para inversiones tecnológicas, profundizando la participación de la banca privada y multilateral en estas tareas.

vi) Explorar fondos de seguro de garantía para inversiones de cierto riesgo tecnológico y un sistema de capital de riesgo para tales inversiones.

vii) Proveer estímulos especiales a exportaciones de ingeniería, servicios y manufacturas intensivas en diseño.

viii) Privilegiar políticas de difusión tecnológica y extensionismo industrial. Favorecer la organización de viajes empresariales y laborales a empresas modernas en el exterior, a centros tecnológicos.

ix) Desarrollar modalidades de subsidio a la pequeña y mediana empresa (PYME) que financien parcialmente consultorías tecnológicas para la modernización de la gestión y los procesos industriales, procesos de normalización y de control de calidad, preparación de proyectos de inversión, presentación de proyectos ante la banca privada, viajes de negocios.

x) Desarrollar una más activa política de becas de posgrado, en función de las prioridades tecnológicas nacionales.

xi) Incorporar en la política de compras públicas criterios que faciliten el desarrollo de proveedores en armonía con las condiciones de competencia internacional.

xii) Promover compromisos con la inversión extranjera en materia de asimilación tecnológica y desarrollo de proveedores de bienes y servicios con mayor contenido tecnológico.

xiii) Mejorar los incentivos a la transferencia tecnológica, servicios y asistencia técnica y avanzar en acuerdos bilaterales que eviten la doble tributación.

\section{Capacitación}

"Completar" el mercado de capacitación es otro eje de la política de desarrollo productivo. Aquí el principal desafío es colocar el tema en un lugar relevante de la agenda nacional, en términos de recursos y de inserción institucional. Una vez conseguido esto, restará abordar las tareas vinculadas a la cobertura, la calidad de la oferta, la flexibilidad institucional, la articulación con las empresas y la adecuación de tiempos y contenidos curriculares a la demanda.

No se trata de que el sector público enumere y defina los contenidos de los cursos ni que los provea directamente. Pero sí le corresponde un papel articulador insustituible: deberá mejorar el diagnóstico sobre las necesidades de capacitación por sectores, regiones y tamaños de empresa; procesar y difundir esa información; estimular y subsidiar la formación de empresas de capacitación, y establecer indicadores que permitan evaluar los resultados y la calidad de la capacitación ofrecida. La tarea pública entonces se remite a favorecer la articulación de la oferta y la demanda, regular el contenido, la calidad y la pertinencia de las actividades y mejorar los incentivos para fomentar la capacitación de empresarios y trabajadores. Esta tarea se realizará con menor costo y mejores resultados si el sector público actúa en instancias tripartitas, con organizaciones empresariales y de trabajadores, y se apoya en consultoras privadas para tareas específicas.

Para mejorar la pertinencia de la capacitación es necesario fortalecer las señales que dan las empresas a los organismos ejecutores. Los vínculos del sistema de capacitación con la educación técnica profesional aún son débiles, y en algunos casos no hay mecanismos de homologación curricular que permitan transitar entre ellos. Colaboraría a resolver este problema un sistema de certificación de competencias, con participación directa de las empresas privadas y públicas, que permita medir las destrezas adquiridas y que opere con estándares reconocidos en el mercado de trabajo. Se fortalecería así el vínculo entre la capacitación y el sistema de educación secundario y técnico postsecundario, con avances en la acreditación de destrezas, y el establecimiento de módulos que permitan la homologación curricular.

Para conocer cabalmente las necesidades de capacitación de las empresas, asegurando así la pertinencia de la que se les ofrece, se puede vincular el diseño y financiamiento de cursos a compromisos de empresas específicas en materia de prácticas la- 
borales, o a contratos de trabajo para los beneficiarios.

La experiencia del Servicio Nacional de Capacitación y Empleo (SENCE) en Chile muestra la importancia de liberar a la estructura central del organismo de labores operativas y funciones adminstrativas - como compras, realización de pagos y supervisión de programas - que pueden ser realizadas por entidades privadas. Al externalizarse tales funciones, esa estructura central puede concentrarse en la formulación de políticas y programas; en los sistemas de información para usuarios en intermediación laboral y capacitación; en la promoción y difusión de políticas y programas, y en la coordinación de programas y actividades con los de otras instituciones públicas que operan en este ámbito. La experiencia muestra también la importancia de favorecer la coordinación interinstitucional, buscando mejorar la coherencia de las diversas políticas, programas y acciones de capacitación, y ligar más la capacitación con las políticas de fomento productivo y tecnológico y con el seguro de desempleo. En todas estas áreas es imprescindible promover la participación empresarial y de los trabajadores para respaldar la certificación de competencias, la detección oportuna de necesidades y la evaluación permanente de las políticas públicas de capacitación.

En síntesis, es necesario estimular el gasto de las empresas en capacitación, adecuando incentivos tributarios y financieros para ello. Cabe también readecuar las instituciones públicas de capacitación, ampliando la participación directa de las empresas y las agrupaciones empresariales en su orientación, dotándolas de más criterios de mercado en su gestión y vinculando los programas de capacitación a las prioridades tecnológicas.

\section{Política de Infraestructura}

Hay un vínculo estrecho entre la calidad de la infraestructura y la capacidad competitiva de una economía. Buena parte de las ventajas competitivas construidas en el Sudeste asiático derivan de una crucial confluencia entre la calidad del recurso humano y de la infraestructura. En tal sentido, el desarrollo de nuevos sistemas de infraestructura, y especialmente su complementariedad e integración con las redes internacionales existentes, es un área estratégica del desarrollo exportador.

El sostenido incremento de la actividad exportadora e importadora planteará presiones de demanda sobre los servicios de energía, telecomunicaciones, caminos, ferrocarriles, puertos y aeropuertos. Estas podrían afectar la competitividad, si es que no se han programado las inversiones de reposición, de ampliación de capacidad y de actualizacion tecnológica en estos sectores.

La contribución de la infraestructura al fomento de la competitividad es doble. Por un lado, puede reducir costos y tiempos de traslado de bienes y servicios a los mercados de destino. Por el otro, con adecuadas innovaciones institucionales que amplíen el espacio de acción de los privados en el financiamiento y gestión de la infraestructura, es posible:

i) incrementar el flujo de recursos asignados al sector, incorporando recursos privados;

ii) racionalizar la toma de decisiones para lograr un uso eficiente de los recursos;

iii) favorecer su descentralización, y

iv) liberar recursos para que el sector público pueda concentrarse en brindar un acceso adecuado a los servicios básicos de los sectores de menores ingresos.

El elemento articulador de estos objetivos es conseguir que los usuarios paguen realmente por el uso, mantención y operación de la infraestructura pública, vale decir, fortalecer los criterios económicos que vinculan el uso de la infraestructura con su precio, subvencionando explícitamente cuando haya razones sociales que lo justifiquen.

Ello, además de las sanas repercusiones sobre la eficiencia en la asignación de recursos, al terminar con la difundida creencia de la gratuidad en la provisión de la infraestructura pública, tiene también favorables efectos sobre la equidad, en tanto establece un vínculo más directo entre uso y pago, liberando recursos para el sector público que pueden destinarse a obras de infraestructura básica, con mayor contenido social. Entre estas obras se encuentran, por ejemplo, las de infraestructura sanitaria básica, agua potable, alcantarillado, pavimentación de calles en barrios populares, construcción de caletas pesqueras y obras de riego menores.

Por ejemplo, financiar la red vial mediante impuestos generales constituye un subsidio, en tanto que los usuarios de carreteras se ven liberados de cancelar por su uso efectivo, de manera que siempre encontraremos allí un exceso de demanda. Es además un subsidio inequitativo, ya que aquellos sectores de menores ingresos, particularmente los radicados en regiones apartadas, contribuyen proporcionalmente más al financiamiento que al disfrute de esa red. 


\section{VII}

\section{Concertación estratégica y calidad de la}

\section{gestión pública}

\section{Papel concertador}

La mayor o menor eficacia de la política industrial estará muy ligada a su capacidad de constituir consensos básicos en torno a la estrategia de desarrollo, y a la imagen productiva, ocupacional y tecnológica que se promueva como proyecto-país.

No podrán estar ausentes en ella temas como la modernización de las relaciones laborales, la responsabilidad ambiental y una concepción global de la economía que concilie competitividad, flexibilidad, estabilidad económica y equidad. También tendrán su lugar los debates sobre un nuevo tipo de empresa, una mayor flexibilidad en los mercados y el estímulo a las relaciones de cooperación dentro de las empresas, entre empresas, y entre ellas y el sector público.

En economías abiertas, las desigualdades excesivas y la debilidad institucional para procesar los conflictos incrementan el riesgo inherente al país y afectan la competitividad. Por lo tanto, el fomento de la competitividad y los avances en la internacionalización de la economía deben ir acompañados de consensos nacionales que den más cabida al tratamiento de la equidad y los temas distributivos. Dicho tratamiento debe adecuarse a su vez a las condiciones de competitividad y flexibilidad que demandan las economías abiertas.

Bien abordadas, tales preocupaciones no son contradictorias con el objetivo de elevar la competitividad. En efecto, estimular la cooperación tripartita en materia de capacitación, acuerdos de productividad, relaciones laborales, calidad e innovación tecnológica, que son tareas nacionales, sirve simultáneamente a los objetivos de competitividad y equidad.

Propiciar la "asociatividad" y las relaciones de colaboración entre agentes públicos y privados puede ser un instrumento decisivo para estimular la productividad y la innovación tecnológica a través, por ejemplo, de centros privados de creación y transferencia tecnológica, orientados a sectores específicos y apoyados en gremios y asociaciones empresariales.

\section{Articulación y alianzas estratégicas}

En el marco de una economía global en la que la actividad exportadora tiende a articularse en redes y alianzas estratégicas, las políticas públicas deberían ayudar a la organización de los actores privados 18 y mejorar la coordinación de los esfuerzos públicos y privados en el exterior, a través de esfuerzos unívocos, de diseño unificado y de carácter nacional.

Para ello, el sector público debería promover entre los actores económicos la elaboración de visiones de largo plazo compartidas en materia de exportaciones, inversión y tecnología, teniendo en cuenta los datos y tendencias internacionales. La principal función pública sería entonces la de concertar posiciones y llegar a acuerdo en el diagnóstico, en la identificación de las principales insuficiencias nacionales y en las líneas de política más importantes.

La estrategia de internacionalización debe ser compartida y estar basada en el consenso sobre la orientación exportadora del proyecto nacional de desarrollo. Mientras más sólidas sean las estrategias privadas en este campo - por ejemplo, con expresión regional y sectorial- más posible será avanzar en estrategias nacionales de inserción inturnacional; el fortalecimiento de las organizaciones privadas a nivel sectorial favorecerá la relación del sector público con los exportadores. Tal consenso y la estabilidad de los incentivos permite llevar a cabo una política comercial más activa, comprometiendo a los ministerios sectoriales con el objetivo exportador.

\footnotetext{
18 A modo de ejemplo, se ha sugerido la posibilidad que el sector público otorgue reducciones tributarias acotadas a las empresas exportadoras que dediquen esa rebaja, más un monto similar, a robustecer la actividad gremial. Tales recursos podrían orientarse a financiar el apoyo técnico a las agrupaciones de exportadores, para mejorar su capacidad de análisis tecnológico, comercial y de las relaciones económicas internacionales, en general. Esto ayudaría a que el sector público contase con una contraparte más documentada y propositiva, mejorando así la capacidad global de delinear estrategias de comercio exterior.
} 
Para avanzar hacia una economía con mayor capacidad de innovación es preciso que se efectúen cambios institucionales en la empresa y en el sector público. La modernización tecnológica es un requisito indispensable en el actual escenario internacional. Hay, sin embargo, diversos modos de abordarla. A mayor consenso entre los diversos actores sociales, mayor será la capacidad de movilizar recursos, instituciones y voluntades en torno a las políticas de modernización productiva. Una modernización tecnocrática puede ser inviable o, peor aún, malograr buenas opciones técnicas de readecuación productiva y tecnológica.

El trabajo en equipo, la exploración conjunta de nuevos escenarios, los diagnósticos consensuales y la concertación estratégica de los actores son prácticas ya frecuentes en los negocios internacionales, en el desempeño reciente de las empresas transnacionales, en las empresas mixtas y en las empresas "virtuales". Incorporar tales prácticas en las instituciones políticas y en el comportamiento social parece ser el verdadero desafío para acceder a modalidades de transformación productiva con equidad. De allí la necesidad urgente de innovación en las instituciones y en el comportamiento de los actores sociales, para adecuarse a modalidades de economía abierta con vistas a instaurar la cooperación social como requisito cultural, y la participación como requisito de eficiencia para el cambio.

\section{Calidad de la gestión pública}

La calidad de la intervención pública dependerá de la coherencia institucional, de una clara delimitación de pocos objetivos, de la eficacia de los instrumentos y de la capacidad administrativa y funcionaria. Esto obliga a ser muy selectivo al plantearse objetivos, para no sobrestimar las capacidades del gobierno.

Más que la cantidad, importa la calidad de la intervención pública en la estructura productiva, la que debe estar en consonancia con los desafíos de innovación institucional que plantea la internacionalización.

Se necesita un sector público más calificado para apoyar las tareas de fomento productivo, regulación y estímulo a la calidad y la competitividad; con fuerte legitimidad social para estimular consensos amplios sobre las nuevas tareas del desarrollo, y con un desempeño transparente, controlable y sujeto a estrictos criterios de evaluación de resultados.

Para alcanzar objetivos más ambiciosos en política industrial se precisa un sector público más sofisticado. Cuando no hay garantía de que éste lo sea, el peso de la prueba corrresponderá al innovador; cuando sea necesario innovar, el primer paso deberá ser el de construir los acuerdos público-privados y las condiciones institucionales que faciliten el nuevo desempeño del sector público. En este y en otros campos es tan peligroso subestimar las imperfecciones del mercado como sobrestimar las capacidades del sector público.

\section{Bibliografía}

Atiyas, I., Mark Dutz y C. Frischtak (1992): Fundamental Issues and Policy Approaches in Industrial Restructuring, Industry Series Paper, $\mathrm{N}^{\circ}$ 56, Washington, D.C., Banco Mundial, Departamento de Industria y Energía.

Banco Nacional de Comercio Exterior (1993): Comercio Exterior, vol. 43, No 9, México, D.F., S.N.C.

CEPAL (1991): Cambios estructurales en los puertos y la competitividad del comercio exterior de América Latina y del Caribe, Cuadernos de la CEPAL, No 65, LC/G.1633-P, Santiago de Chile. Publicación de las Naciones Unidas, $\mathrm{N}^{\circ}$ de venta S.90.II.G.10.

(1992a): Equidad y transformación productiva: un enfoque integrado, LC/G.1701/Rev. 1-P, Santiago de Chile. Publicación de las Naciones Unidas, $\mathrm{N}^{\circ}$ de venta S.90.II.G.10.

(1992b): Los nuevos escenarios agrícolas en formación, LC/L.707, Santiago de Chile.

(1993a): La apertura y los procesos agroexportadores recientes, LC/R.1299, Santiago de Chile.

(1993b): Seminario regional sobre la normativa del transporte multimodal: sintesis y conclusiones, LC/R.1324, San- tiago de Chile, Asociación Latinoamericana de Integración (ALADI/CEPAL).

(1994a): Políticas para mejorar la inserción en la economía mundial, LC/G.1800 (SES.25.3), Santiago, Chile.

(1994b): La Cumbre Social: una visión desde América Latina y el Caribe (Nota de la Secretaría), LC/G.1802 (SES.25.5), Santiago de Chile, 5 de enero.

CET (Centro de las Naciones Unidas sobre las Empresas Transnacionales) (1991): World Investment Report 1991. The Triad in Foreign Direct Investment, Nueva York. Publicación de las Naciones Unidas, $\mathbf{N}^{\circ}$ de venta E.91.II.A.12.

Drucker, P. (1993): Administración y futuro. De los '90 en adelante, Buenos Aires, Editorial Sudamericana.

Jorde, Th. y D. Teece (1990): Innovation and cooperation: Implication for competition and antitrust, The Journal of Economic Perspective, vol. 4, $\mathrm{N}^{\circ} 3$, Nashville, Tennessee, American Economic Association.

Krugman, P. (1991): Una política comercial estratégica para la economía internacional, P. Krugman (comp.), Introducción, México, Fondo de Cultura Económica. 
(1994): Competitiveness: a dangerous obsession, Foreign Affairs, vol. $73, \mathrm{~N}^{\circ} 2$, marzo-abril.

Lafay, G. (1989): Commerce international: La fin des avantages acquis, París, Centro de información y estudios prospectivos internacionales/Ed. Económica.

Lambsdorff, O. (1993) Fascination with the inmediate, International Economic Insights, vol. IV, $\mathrm{N}^{\circ} 2$, Washington, D.C., Institute for International Economics.

OCDE (Organización de Cooperación y Desarrollo Económicos) (1992): Industrial Policy in OECD Countries. Annual Review 1992, París, OCDE.

Peres, W. (1993): ¿Dónde estamos en política industrial?, Revista de la CEPAL, N N $^{\circ}$ 1, LC/G. 1792-P, Santiago de Chile, Naciones Unidas.

Pérez, C. (1988): Tendencias en la industria mundial: nuevos elementos de la competitividad, Seminario Estrategia Industrial, Proyecto Fomento-ONUDI, Caracas.

Romer, P. (1992): Two strategies for economic development: Using ideas and producing ideas, Proceedings of The World Bank
Annual Conference on Development Economics 1992 (30 de abril/1 de mayo), Washington, D.C., Banco Mundial.

Rosales, O. (1993): Perspectivas de la economía chilena en el contexto de la economía mundial; escenarios posibles, I. Valenzuela (ed.), Chile exporta minería, Santiago de Chile, Editec Ltda.

(1994): Desempeño reciente de los NIC's asiáticos: políticas e instrumentos de fomento competitivo, CEPAL, documento de trabajo, mimeo.

Schliessler, A. y A. Bull (1992): Caminos. Un nuevo enfoque para la gestión y conservación de redes viales, LC/L.693, Santiago de Chile, CEPAL.

Solow, R., M. Dertouzos y R. Lester (1989): Made in America: Regaining the Productive Edge, Cambridge, Mass., MIT Press.

Stiglitz, J. (1989): Markets, market failures, and development, American Economic Review, vol. 79, No 2, Nueva York, American Economic Association.

Tavares de Araújo Jr., J. (1993): The scope for industrial policy in a free trade environment, Revista de economía política, vol. 13, N³ (51), São Paulo, Centro de Economía Política.

ANEXO 1

\section{Instrumentos de apoyo a la competitividad en algunas experiencias asiáticas}

\section{Hong Kong}

Capacitación. Impuesto de 30 centavos por cada mil dólares exportados en prendas de vestir y calzados. Los fondos se utilizan en la capacitación de trabajadores del mismo sector.

Seguimiento de la evolución de la competitividad. El Consejo de Desarrollo Industrial, que incorpora industriales, funcionarios públicos, de universidades, centros tecnológicos y organizaciones empresariales, realiza investigaciones técnicas y económicas sobre industrias importantes, define perspectivas y detecta obstáculos para actualizar el aporte estatal.

Productividad. El Consejo para la Productividad organiza misiones de estudio de tecnología y técnicas en el extranjero para industriales locales; provee servicios de adiestramiento, asesoría, asistencia técnica y de laboratorio en áreas de la productividad industrial, y realiza también actividades de consultoría, capacitación, exposiciones industriales, servicios de información industrial y actividades de enlace de centros tecnológicos con empresas industriales.

Promoción comercial. El Consejo de Desarrollo Comercial provee servicios de investigación e información comercial y servicios de promoción de la diversificación de productos y mercados y de mejoras en la calidad, diseño, presentación e imagen de los productos. Se financia con cuotas canceladas por las empresas establecidas en el país.

Tecnologías modernas. La Corporación de Polígonos Industriales está orientada a apoyar el estable- cimiento de industrias intensivas en tecnología que requieren grandes espacios físicos, facilitando terrenos y servicios.

\section{Singapur}

Capacitación. El Fondo para el Fomento de la Capacitación, al que los empleadores aportan $1 \%$ de la planilla salarial, está abierto a todos para la capacitación y readecuación de sus trabajadores. El Fondo otorga además incentivos financieros a los empleadores por medio de varios programas de donaciones para capacitación.

Internacionalización: La Junta de Fomento del Comercio de Singapur, encargada de la promoción exportadora, hoy alienta y ayuda a que las empresas establezcan oficinas en el extranjero, mejoren el diseño de productos y embalajes, comercialicen nuevos productos y servicios y participen en licitaciones para obtener contratos en el exterior.

Apoyos tributarios a la exportación. Exención parcial del impuesto a las empresas. Las empresas manufactureras que exporten más de 60000 dólares o el $20 \%$ de sus ventas anuales totales cuentan con una exención parcial del impuesto (respecto del $90 \%$ de los beneficios adicionales por encima de la base de exportación; el período de exención suele ser de cinco años y la base de exportación, el promedio de los beneficios de exportación de los últimos cinco años). Los gastos derivados de participación en ferias, exposiciones, misiones comer- 
ciales, gastos de publicidad, en comunicaciones y mantenimiento de oficinas comerciales en el exterior, están afectos a doble deducción en la renta bruta, para efectos tributarios.

Incentivos fiscales para la economía global. Asistencia técnica en investigación y desarrollo, perfeccionamiento del diseño y elaboración de productos, mejoramiento de normas y calidad, capacitación del personal técnico y de gestión. Incluye beneficios adicionales por la condición de "precur- sor", incentivos a la expansión, desgravación de inversiones, préstamos extranjeros para adquisición de equipo productivo y deducciones por depreciación acelerada.

Ayuda para investigación y desarrollo. Las subvenciones a las empresas cubren del 30 al $70 \%$ de los costos directos de los proyectos pertinentes de las empresas. Se puede conceder una desgravación fiscal de hasta el $50 \%$ de la inversión fija en este campo. 